\title{
Myomectomy Revisited: Experiences in a Teaching Hospital
}

\author{
Shanti Subedi, ${ }^{1}$ Manisha Chhetry, ${ }^{1}$ Sabina Lamichhane ${ }^{1}$ \\ 'Department of Obstetrics and Gynaecology, Nobel Medical College, Biratnagar, Nepal.
}

\section{ABSTRACT}

Introduction: Uterine myomas are the most common benign tumors of the female reproductive tract with myomectomy being one of the major modalities of the treatment in our set up. The aim of this study was to share the experiences of open myomectomy from a Teaching Hospital.

Methods: A observational study was conducted from a records of myomectomy cases in the department of Obstetrics and Gynaecology at Nobel Medical College teaching Hospital from June 2014- May 2016.

Results: Total 38 cases of myomectomy were performed during the study period in the women most commong age group being 35-39 years, followed by 30-34. The most common presenting symptoms was abnormal uterine bleeding in $15(39.47 \%)$ followed by mass per abdomen in $10(26.31 \%)$. The most common location of the myoma was intramural followed by subserosal, submucus. Degeneration was also noted in majority of the cases. All the myomectomies were done with Inj Vasopressin injected paracervically except in one case where tourniquet was used. None of the patients had significant post-operative morbidity except fever in the first 24 hours.

Conclusions: Abdominal myomectomy is a safe and effective procedure for uterine myomas for infertile women in the past but it should be offered to those desiring for uterine preservation irrespective of age and reproductive status.

Keywords: abnormal uterine bleeding; degeneration; myomectomy.

\section{INTRODUCTION}

Uterine leiomyomas are the most common benign tumors of smooth muscles of the female reproductive tract. Although most of them are asymptomatic but 20$50 \%$ of them can cause menstrual abnormality in the form of menorrhagia, pelvic pain or pressure, colorectal or urinary complaints. ${ }^{1}$ Myomas are estimated to occur with increased frequency during the later reproductive years. ${ }^{2}$

Myomectomy is a surgical procedure in which myoma is removed while the uterus is preserved in women of child bearing age. ${ }^{3}$ But this concept has been changed as the organ preserving surgery is gaining popularityin the recent days.
Myomectomy can be done by laparotomy, laparoscopy, vaginally and hysteroscopically. This study focuses on myomectomy done for various myomas of the female genital tract.

\section{METHODS}

A observational study was conducted from a records of myomectomy cases in the department of Obstetrics and Gynaecology at Nobel Medical College teaching Hospital from June 2014 - May 2016. Ethical approval was taken. The records were obtained from register from OT, Gynaecology ward and record section. All case of myomectomy was included from the study

Correspondence: Dr. Shanti Subedi, Department of Obstetrics and Gynaecology, Nobel Medical College, Biratnagar, Nepal. Email: subedi007@gmail.com, Phone: +977-9842021806. 
period. Date were collected and analysed in statistical package for social sciences for windows.

\section{RESULTS}

Total 38 cases of myomectomy were performed during the study period were analyzed. Regarding the age group of the women ranged from $2(5.2 \%)<25$ years, $3(7.8 \%) 25-29$ years, $10(26.3 \%) 30-34$ years, 15 $(39.4 \%) 35-39$ years, $40-44$ years $6(6 \%)$, and $2(5.2 \%)$ $>45$ years (Table 1 ). Out of them 10 were unmarried ladies. The parity was 0-2 in majority of women.

\begin{tabular}{|ll|}
\hline \multicolumn{2}{|c|}{ Table 1. Socio-demographic status of the patients. } \\
\hline A. Age ( years) & $\mathrm{n}(\%)$ \\
$<25$ & $2(5.2 \%)$ \\
$25-29$ & $3(7.8 \%)$ \\
$30-34$ & $10(26.3 \%)$ \\
$35-39$ & $15(39.4 \%)$ \\
$40-44$ & $6(6 \%)$ \\
$>45$ & $2(5.2 \%)$ \\
B. Marital Status & \\
Married & $28(73.6 \%)$ \\
Unmarried & $10(26.3 \%)$ \\
\hline
\end{tabular}

Presenting symptoms of the patients include 15 (39.4\%) abnormal uterine bleeding, 10 (26.3\%) mass per abdomen and $7(18.4 \%)$ Dysmenorrhoea (Table 2). Some patients had more than one symptoms.

\begin{tabular}{|ll|}
\hline Table 2. Presenting symptoms. \\
\hline Symptoms & $\mathrm{n}(\%)$ \\
Abnormal uterine bleeding & $15(39.4 \%)$ \\
Mass per abdomen & $10(26.3 \%)$ \\
Dysmenorrhoea & $7(18.4 \%)$ \\
Infertilty & $5(13.1 \%)$ \\
Recurrent abortion & $1(2.6 \%)$ \\
\hline
\end{tabular}

With respect to location, 20 (52.6\%)intramural being the commonest variety, followed by $7(18.4 \%)$ subserosal, $4(10.5 \%)$ submucous, $4(10.5 \%)$ broad ligament and $3(7.8 \%)$ cervical. Maximum number of myoma found was total 12 including intramural and subserosal. Pre-operative uterine size of 16-24 was 15 (39.4\%) (Table 4).

\begin{tabular}{|lc|}
\hline \multicolumn{2}{|l|}{ Table 3. Types of Myoma at Operation. } \\
\hline Types & $\mathrm{n}(\%)$ \\
Intramural & $20(52.6 \%)$ \\
Subserosal & $7(18.4 \%)$ \\
Submucus & $4(10.5 \%)$ \\
Broad Ligament & $4(10.5 \%)$ \\
Cervical & $3(7.8 \%)$ \\
\hline
\end{tabular}

\begin{tabular}{|ll|}
\hline Table 4. Pre-operative uterine size. \\
\hline Pre-operative uterine size (weeks) & $\mathrm{n}(\%)$ \\
$\leq 10-12$ & $4(10.5 \%)$ \\
$12-16$ & $12(31.5 \%)$ \\
$16-24$ & $15(39.4 \%)$ \\
$\geq 24-28$ & $7(18.4 \%)$ \\
\hline
\end{tabular}

Abdominal myomectomy was done successfully except for three cases of cervical myoma which was done through vaginal route. One case of vaginal myomectomy was converted to abdominal hysterectomy because of hemorrhage. Cavity was opened in 10 cases during surgery for which Cu-T was kept in 8 cases which was removed after 6 weeks.

Cut section of the myoma revealed different degeneration including $8(21 \%)$ cystic, $3(7.8 \%)$ fatty and $3(7.8 \%)$ calcification.

All the myomectomies were done with Injection Vasopressin diluted in $19 \mathrm{ml}$ of Saline given paracervically except in one case where tourniquet was tied in such away that it temporarily impedes the blood supply from the uterine vessels and the infundibulo-pelvic ligament . The tourniquet was released for intermittently at about 20 minutes interval and then it was removed after repair of the uterus.

Duration of operation was between $60-80$ minutes depending on the location and size of the myoma and operative blood loss varied from $300-600 \mathrm{ml}$. and only one case had blood loss of $>800 \mathrm{ml}$ that ultimately required abdominal hysterectomy. None of the patients had significant post-operative morbidity except for fever in the first 24 hours.

\section{DISCUSSION}

Abdominal myomectomy is an old surgical procedure and a well established alternative to hysterectomy for women to preserve their fertility. ${ }^{4,5}$ It was a feared practice in older days and thus limited for reasons of fertility. But this concept has been changed in the recent era as organ preserving surgery is gaining popularity. So it should be offered to women who want to preserve the uterus despite their age and reproductive status. As different studies concluded that myomas are the tumors occurring in reproductive age $<35$, this necessitates removal of the tumor alone..$^{6,7}$

Though myomectomy was considered appropriate surgical modality in young age but here it was done in women beyond the age of 40 and few cases in the perimenopausal age in view of feeling the youth and patient satisfaction. In a study done by Radosa MP et al $^{8}$ showed high satisfaction and significantly lower 
number of relapse after myomectomy being done in peri -and post-menopausal women. However a chance of recurrence must be perceived in all these young women. Studies have shown that all the myoma above 10 weeks or multiple myomas have predisposition for recurrence. ${ }^{9}$

Here we have done almost all the myomectomies with Inj. Vasopressin diluted in $19 \mathrm{ml}$ of Saline injected paracervically that reduced our operative time because of increasity clarity of the surgical field. Local administration of Vasopressin is a safe and effective hemostatic technique for controlling regional blood flow from the uterine vessels to the peripheral vessels, without having a significant effect on systemic circulatory dynamics. Several studies showed that using vasoconstrictive agents during myomectomy reduces the operative time. ${ }^{10,11}$
Pregnancy after myomectomy is possible but it was not that significant in our study as women of our society fear cohabitation in the immediate post operative period and afterward. In the study conducted by Soriano $D$ et al ${ }^{12}$ showed that pregnancy rate before myomectomy was $20 \%$ and $70 \%$ after myomectomy and pregnancy loss was $69 \%$ and $85 \%$ and live birth rate was $30 \%$ and $75 \%$ respectively. This appears to be additional benefit of myomectomy.

\section{CONCLUSIONS}

Abdominal myomectomy is a safe and effective procedure for uterine myomas for infertile women in the past but it should be offered to those women desiring for uterine preservation irrespective of age and reproductive status

\section{REFERENCES}

1. Buttram VC, Jr, Reiter RC. Uterine leiomyomata: etiology, symptomatology, and management. Fertil Steril. 1981; 36(4):433-45.

2. Chen I, Lisonkova S, Joseph KS, Williams C, Yong P, et al. Laparoscopic versus abdominal myomectomy: practice patterns and health care use in British Columbia. J Obstet Gynaecol Can. 2014;36:817-21.

3. Myers ER, Barber ND. Management of uterine leiomyomata: What do we really know? Am J Obstet Gynecol. 2002;100:8-17.

4. Farquhar C, Brown PM, Furness S. Cost effectiveness of pre- operative gonadotrophin releasing analogues for women with uterinefibroids undergoing hysterectomy or myomectomy. BR J Obstet Gynecol. 2003;110:712-3.

5. Roth TM, Gustilo-Ashby T. Effects of race and clinical factors on short-term outcomes of abdominal myomectomy. Am. J Obst Gynecol. 2003;101:881-4.

6. Aboyeji, AP, Ijaiya MA. Uterine fibroids: A ten year clinical review in IIorin, Nigeria. Niger J Med. 2002;11(1):16-9.
7. Omu AE, ihejerica IJ, Tabowei G. Management $f$ uterine fibroids at the University of Benin Teaching Hospital. Trp Doct. 1984;14(2):82-5.

8. Radosa MP, Winzer H, Mothes AR, Camara O, Diebolder H, Weisheit A et al. Laparoscopic myomectomy in peri-and post -menopausal women is safe and efficacious and associated with long term patient satisfaction. Eur J Obstet Gynecol Reprod Biol.2012;162(2):192-6.

9. Hanafi M. Predictors of leiomyoma recurrence after myomectomy. Obstet gynecol 2005;105(4):877-81.

10. Frederick J, Fletcher H, Simeon D, Mullings A, Hardie M. Intramyometrial vasopressin as a hemostatic agent during myomectomy. Br J Obstet Gynecol. 1994;101:435-7.

11. Sizzi O, Rossetti a, MalzoniM, Minelli L, La Grotta f, SorannaL et al. Italian multicenter study on complications of laparoscopic myomectomies. J Minim Invasive Gynecol. 2007;14:453-62.

12. Soriano D, Dessolle L, Poncelet C, Benefia JL, Madelenet $\mathrm{P}$, darai E. Pregnancy outcome after laparoscopic and lapro converted myomectomy. Eur J Obstet Gynecol. 2003;108:194-8. 